\title{
«Astérion» 16. Traductions vers le latin au XVI siècle, dir. Martine Furno
}

\section{Maurizio Busca}

\section{OpenEdition}

\section{Journals}

\section{Edizione digitale}

URL: http://journals.openedition.org/studifrancesi/10543

DOI: 10.4000/studifrancesi. 10543

ISSN: 2427-5856

\section{Editore}

Rosenberg \& Sellier

\section{Edizione cartacea}

Data di pubblicazione: 1 décembre 2017

Paginazione: 539

ISSN: 0039-2944

\section{Notizia bibliografica digitale}

Maurizio Busca, ««Astérion» 16. Traductions vers le latin au xve siècle, dir. Martine Furno», Studi Francesi

[Online], 183 (LXI | III) | 2017, online dal 01 février 2018, consultato il 22 janvier 2021. URL: http:// journals.openedition.org/studifrancesi/10543 ; DOI: https://doi.org/10.4000/studifrancesi.10543

Questo documento è stato generato automaticamente il 22 janvier 2021.

\section{(a) $\odot \Theta$}

Studi Francesi è distribuita con Licenza Creative Commons Attribuzione - Non commerciale - Non opere derivate 4.0 Internazionale. 


\title{
«Astérion» 16. Traductions vers le latin au XVI siècle, dir. Martine Furno
}

\author{
Maurizio Busca
}

\section{NOTIZIA}

«Astérion» 16. Traductions vers le latin au XVI siècle, numéro sous la direction de Martine FURNO, 2017 (URL: https://asterion.revues.org/2877).

1 La rivista Astérion dedica un numero monografico alle traduzioni dal greco, dall'ebraico e dalle lingue vernacolari al latino nel Cinquecento. Traduzioni che, da un punto di vista quantitativo, appaiono minoritarie se comparate a quelle elaborate all'epoca in lingua francese e che, rispetto a queste ultime, sono state oggetto di studi meno sistematici.

Le traduzioni latine, come segnala FURNo nella sua introduzione (Chronique d'un figement annoncé: les traductions vers le latin au XVI siècle: https://asterion.revues.org/2891), sono generalmente elaborate in vista di una pubblicazione rivolta a un pubblico preciso: di conseguenza, le caratteristiche del libro prodotto (formato, presenza del testo originale e di commenti) dipendono spesso da logiche di tipo editoriale e commerciale. Lo studio di Ioannis DeLIGIANNIS sulle traduzioni latine di Luciano (Production et diffusion des traductions latines de Lucien à la période de la fin du manuscrit et des débuts de l'imprimé: fin $X V^{e}$ siècle-fin XVI $I^{e}$ siècle: https://asterion.revues.org/2896) illustra bene tali dinamiche. Nel secondo Quattrocento, le traduzioni degli umanisti italiani godono di una buona circolazione manoscritta e a stampa e permettono di far conoscere le opere lucianee in Europa; a partire dal primo Cinquecento aumenta sensibilmente il numero di traduttori (non solo italiani: grande successo hanno le versioni di Erasmo, Thomas More e Melanchthon), compaiono volumi bilingui in cui il testo latino funge da supporto alla comprensione del testo originale e, grazie alla diffusione dello studio del greco, sono stampati anche volumi monolingui. Il numero di edizioni latine di Luciano cala solo a partire dalla metà del secolo, di fronte all'apparizione delle traduzioni in lingue 
vernacolari e alla crescente ostilità della Chiesa cattolica e protestante verso questo autore. I decenni centrali del Cinquecento non costituiscono tuttavia un periodo di crisi per la traduzione latina nel suo insieme: il latino, infatti, è ancora la lingua privilegiata per la traduzione di testi filosofici. Laurence BERNARD-PRADELLE (Denis Lambin "versus" Joachim Périon: quel style pour traduire Aristote?: https://asterion.revues.org/2909) guarda al lavoro di due traduttori dell'Etica nicomachea, Périon e Lambin, i quali si interrogano non già sulla lingua, ma sullo stile più opportuno per tradurre Aristotele. Entrambi adottano senza esitazioni il latino ma, se nel 1540 Périon si serve di uno stile ciceroniano, Lambin nel 1572 polemizza con il suo predecessore affermando la necessità di tradurre tentando di rendere fedelmente sia il fondo che la forma del testo originale. Secondo Lambin, il latino, data la sua estrema duttilità, si presenta come l'idioma ideale per tradurre il greco di Aristotele poiché può riprodurne anche lo stile, e il traduttore deve saper impiegare al meglio tale potente strumento linguistico (in queste considerazioni, osserva l'A., Lambin riprende le riflessioni sulla traduzione che Leonardo Bruni aveva formulato nel primo Quattrocento). Le scelte dei traduttori, come osserva Martine FURNo (La traduction latine du "Commentario de le cose de' Turchi" de Paolo Giovio: desseins politiques et destin historiographique (1537-1577): https:// asterion.revues.org/2920), possono inoltre essere dettate da ragioni di ordine ideologico. È in questa prospettiva che viene studiata la traduzione latina del Commentario di Giovio ad opera di Francesco Negri, pubblicata ben cinque volte negli anni 1537-1539 e più tardi inserita nelle raccolte di opere latine dello stesso Giovio. L'A. rileva come la lettura del Commentario venga alterata dagli editori della traduzione di Negri, che la pubblicano in miscellanee contenenti opere di ben altra portata ideologica orientandone in una chiave inedita la ricezione: il commentario nasce come invito indirizzato a Carlo $\mathrm{V}$ a ingaggiare una nuova guerra contro $\mathrm{i}$ Turchi, ma nelle edizioni del 1537-1539 viene utilizzato per sostenere la causa della Riforma. L'ultimo contributo, di Susanna GAMBINO LONGO, è dedicato alla traduzione in latino di opere filosofiche moderne redatte originariamente in lingua volgare, e più precisamente a La traduction latine des "Dialoghi della Historia de Francesco Patrizi da Cherso" par Nicholas Stupan (1570) et la réception européenne de sa théorie de l'histoire (https://asterion.revues.org/2927). La traduzione di Stupan normalizza gli aspetti più originali del lessico e della sintassi di Patrizi: servendosi del latino come di una «langue de clarification et de cristallisation de la pensée», pur senza stravolgere il senso del testo d'origine, Stupan procede a un'uniformazione lessicale che impoverisce semanticamente il discorso, e ciò in particolare per quanto riguarda il lessico politico, scientifico e platonico.

3 I quattro contributi raccolti non intendono certamente fornire un quadro esaustivo del fenomeno delle traduzioni latine nel Rinascimento ma, attraverso gli interessanti casi studio che propongono, permettono di portare uno sguardo su diversi aspetti fondamentali di una pratica che ha favorito la circolazione di saperi in Europa e che, lungi dall'esaurirsi nel Cinquecento, si mostra vitale ancora nel secolo successivo. 